\title{
Comparative Analysis of Sorghum bicolor Proteome in Response to Drought Stress and following Recovery
}

\author{
Christoph Jedmowski, ${ }^{1}$ Ahmed Ashoub, ${ }^{1,2,3}$ Tobias Beckhaus, ${ }^{4}$ Thomas Berberich, ${ }^{2}$ \\ Michael Karas, ${ }^{4}$ and Wolfgang Brüggemann ${ }^{1,2}$ \\ ${ }^{1}$ Institute of Ecology, Evolution, and Diversity, Johann Wolfgang Goethe-University Frankfurt, Max-Von-Laue Straße 13, \\ 60438 Frankfurt, Germany \\ ${ }^{2}$ Biodiversity and Climate Research Centre (BiK-F), 60325, Frankfurt am Main, Germany \\ ${ }^{3}$ Agricultural Genetic Engineering Research Institute (AGERI), ARC, Giza 12619, Egypt \\ ${ }^{4}$ Institute of Pharmaceutical Chemistry, Johann Wolfgang Goethe-University Frankfurt, 60438 Frankfurt, Germany
}

Correspondence should be addressed to Ahmed Ashoub; ashoub@em.uni-frankfurt.de

Received 30 June 2014; Revised 8 September 2014; Accepted 8 September 2014; Published 1 October 2014

Academic Editor: Michael Hippler

Copyright (C) 2014 Christoph Jedmowski et al. This is an open access article distributed under the Creative Commons Attribution License, which permits unrestricted use, distribution, and reproduction in any medium, provided the original work is properly cited.

\begin{abstract}
The adaptive response of Sorghum bicolor landraces from Egypt to drought stress and following recovery was analyzed using twodimensional difference gel electrophoresis, 2D-DIGE. Physiological measurements and proteome alterations of accession number 11434, drought tolerant, and accession number 11431, drought sensitive, were compared to their relative control values after drought stress and following recovery. Differentially expressed proteins were analysed by Matrix assisted laser desorption ionisation timeof-flight mass spectrometry, MALDI-TOF-MS. Alterations in protein contents related to the energy balance, metabolism (sensu Mewes et al. 1997), and chaperons were the most apparent features to elucidate the differences between the drought tolerant and sensitive accessions. Further alterations in the levels of proteins related to transcription and protein synthesis are discussed.
\end{abstract}

\section{Introduction}

Abiotic stresses like drought, salinity, flooding, temperature extremes, and improper agricultural techniques have a negative impact on final yield of cultivated plants [1]. These stressors apart or combined can result in yield reduction of up to $80 \%$ [2]. Water availability is considered a major limitation for plant production [3]. Drought triggers the signal transduction of the phytohormone abscisic acid, ABA, a key hormone involved in stomata closure to reduce transpiration. Drought also suppresses cell growth and photosynthesis efficiency, increases respiration [4], and induces several other genes involved in the response to abiotic stresses [5]. Several drought-inducible genes involved in a broad range of functions have been identified by molecular and genomic analyses in Arabidopsis, rice, and other plants [5, 6]. However, the level of a specific mRNA does not always correlate well with the level of proteins. An mRNA produced in abundance may be degraded rapidly or translated inefficiently, resulting in a nonproportional abundance of mRNA and protein. Moreover, out of a given pool of mRNA, only a fraction is recruited further into the polyribosome assembly for translation [7]. Further, many transcripts give rise to more than one protein, through alternative splicing or alternative posttranscriptional modifications. Additionally, many proteins experience posttranslational modifications that profoundly affect their activities. Drought-inducible genes are classified into two groups. The first group includes proteins that function in abiotic stress tolerance such as chaperones, late embryogenesis abundant (LEA) proteins, osmotin, mRNA-binding proteins, key enzymes for osmolyte biosynthesis, water channel proteins, metabolites transporters, detoxification enzymes, and various proteases. Osmotic adjustment including accumulation of sugar alcohols, amino acids, organic acids, and glycine 
betaine decreases the intracellular osmotic potential. The second group is comprised of regulatory proteins involved in further regulation of signal transduction and stress-responsive gene expression like protein kinases, protein phosphatases, enzymes involved in phospholipid metabolism, and other signaling molecules such as calmodulin-binding protein [8].

Sorghum bicolor L. Moench, a C4 grass, ranks the fifth economically important cereal crop worldwide [9]. The availability of the full genome sequence [10] makes sorghum a C4 model plant in addition to the C3 plants Arabidopsis and rice to study gene products involved in adaptation to drought stress. In our previous study [11] ten Egyptian genotypes of Sorghum bicolor were compared for their drought tolerance using the OJIP test to analyse fast induced chlorophyll fluorescence from photosystem II [12]. In the present study, accession number 11434, drought tolerant, and accession number 11431, drought sensitive, were subjected to proteome analysis using 2D-DIGE system followed by MALDI-TOFMS. The proteome alteration in response to drought conditions and following watering was compared to their relative controls to figure out difference between drought tolerant and sensitive genotypes.

\section{Materials and Methods}

2.1. Plant Materials and Growing Conditions. Accession number 11434, drought tolerant, and accession number 11431, drought sensitive, obtained from the Egyptian National Gene Bank were used in this study. Seeds were germinated in Petri dishes for 48 hours. Three seedlings were planted in $11 \times 11$ $\times 11 \mathrm{~cm}^{3}$ plastic pots filled with $700 \mathrm{~g}$ soil containing $50 \%$ clay, $25 \%$ sand, and $25 \%$ humus. Ten pots/genotype were used in the experiment. Plants were kept in a greenhouse under 16-hour photoperiod with light intensity of $135 \mu \mathrm{mol}$ quant $\mathrm{m}^{-2} \mathrm{~s}^{-1}$ at $24^{\circ} \mathrm{C}$. Field capacity was adjusted to $70 \%$ using an $\mathrm{HH} 2$ moisture meter (Delta-T Devices Ltd.). At the stage of 5 extended leaves, further watering was prevented.

2.2. Drought and Recovery Treatments. To allow drought adaptive response, the soil was left to dry until the level of $10 \%$ field capacity and left further for 7 days without any watering. At the end of drought treatment, the soil water potential was approximately $-2 \mathrm{MPa}$, as measured by a Wescor psychrometer. Following drought treatment, the plants were rewatered till water drain for recovery.

2.3. Physiological Measurements. Leaf relative water content, RWC, was measured for plants under full watering regime following drought treatment and 24 hours following recovery according to Smart and Bingham [13]. Fast chlorophyll fluorescence induction curves to calculate Fv/Fm and $\mathrm{PI}_{\mathrm{abs}}$ as parameters describing the "fitness" of the photosynthetic apparatus [14] were measured between 9 and 10 a.m. following 60 min of dark adaptation on the third leaf of controls (full watered), at the end of the drought treatment, and 24 hours following recovery.
2.4. Samples Collection. Following drought treatment, in total 5 third leaves (from one or two out of the three plants per pot) were collected as bulk immediately after chlorophyll fluorescence measurements, frozen under liquid $\mathrm{N}_{2}$, and stored at $-80^{\circ}$ C. 24 hours after recovery, samples of the third leaves were collected from the remaining plants, frozen under liquid $\mathrm{N}_{2}$, and stored at $-80^{\circ} \mathrm{C}$.

2.5. Protein Extraction, 2D-DIGE-PAGE, and MALDI-TOFMS. Protein extraction was carried out using $200 \mathrm{mg}$ tissue following the established $10 \%$ TCA-acetone extraction protocol [15] with the modification of replacing the $0.07 \%$ 2-mercaptoethanol with $10 \mathrm{mM}$ DTT in the $10 \%$ TCAacetone and absolute acetone. Proteins were resuspended in $1 \mathrm{~mL}$ of resuspension solution (7 M urea and $2 \mathrm{M}$ thiourea). Resuspension was achieved with 3 times sonication on ice, 5 seconds each at $35 \%$ power output using a Sonopuls mini 20 sonicator, and a MS 1.5 probe (Bandelin). Samples were clarified by two subsequent centrifugations at $13000 \mathrm{rpm}$ for 15 minutes at $20^{\circ} \mathrm{C}$. Protein concentration was measured [16] and adjusted to $2 \mathrm{mg} \mathrm{mL}^{-1}$ using resuspension solution. An aliquot of $50 \mu \mathrm{g}$ protein samples was labeled with Cy2, Сy-3, or Cy-5 for control, drought treated, and recovery treated samples, respectively, using Cy-Dye DIGE Fluor Minimal Dye Labeling Kit (GE Healthcare) following the manufacturer's recommendation. Following labeling, samples were mixed together and $200 \mu \mathrm{g}$ of unlabeled protein from drought and recovery plant extracts were added to allow sufficient proteins for MALDI-TOF-MS reaction. Samples were adjusted to $360 \mu \mathrm{L}$ with resuspension solution and $90 \mu \mathrm{L}$ 5X loading buffer, containing 20\% (w/v) CHAPS, $200 \mathrm{mM}$ DTT, $10 \%$ (v/v) IPG buffer $\mathrm{pH} 3-10$, and $0.01 \%$ (w/v) bromophenol blue, was added. Samples were used to rehydrate $24 \mathrm{~cm}$ pH 3-10 nonlinear IEF strips (GE-Healthcare) overnight prior to IEF using the Multiphor II Electrophoresis System (GE-Healthcare) at $70 \mathrm{kV} \cdot \mathrm{h}$. Following IEF and prior to separation on a $20 \mathrm{~cm}$ length $10 \%$ SDS-PAGE [17] casted into low fluorescence glass plates, strips were equilibrated for 15 minutes in $15 \mathrm{~mL}$ of SDS equilibration solution ( $6 \mathrm{M}$ urea, 75 mM Tris- $\mathrm{HCl} \mathrm{pH}$ 8.8, 29.3\% (v/v) glycerol, 2\% (w/v) SDS, and $0.002 \%(\mathrm{w} / \mathrm{v})$ bromophenol blue) containing $1 \%$ DTT, followed by additional 15 minutes in SDS equilibration solution containing $2.5 \%(\mathrm{w} / \mathrm{v})$ iodoacetamide. Following electrophoresis, gels were scanned using a Typhoon 9410 scanner (GE healthcare). Images were analyzed using DeCyder 2-D Differential Analysis Software (GE healthcare). After analysis, gels were stained overnight using colloidal blue stain (Invitrogen). MALDI-TOF-MS was carried out on protein spots excised from polyacrylamide gels as described in Ashoub et al. [18] and the included references. Proteins were identified using Mascot (Matrix Science; peptide mass tolerance: $60 \mathrm{ppm}$; setting of maximum missed cleavages at 1) using the NCBInr database. The criterion for identifying a protein as significant up- or downregulated was a 1.5fold threshold change in relative fluorescence signal intensity by pairwise comparison of the dye signals from the three coelectrophoresed samples [19, 20]. Protein MALDI-TOFMS results with a score above the identification threshold 
$84(P<0.05)$ were considered significant for accuracy of identification.

\section{Results and Discussion}

In this study, a comparison is made between two Sorghum genotypes which differ in their response to drought based on the physiological differences of their photosynthetic apparatus. A soil water potential of approximately - $2 \mathrm{MPa}$ was applied to ensure that plants perceived severe drought under greenhouse conditions. The 2D-DIGE approach was performed to analyze the changes in the proteome after drought stress and following recovery. The study used the MALDI-TOF-MS analysis to identify differentially expressed proteins.

3.1. Physiology. The Fv/Fm parameter representing the maximum quantum efficiency of photosystem II [21] and the performance index, $\mathrm{PI}_{\mathrm{abs}}$, as an indicator of the overall internal strength of the sample to resist external stresses [22] were used as parameters to demonstrate the physiological status of the Sorghum genotypes \# 11434 (drought tolerant) and \# 11431 (drought sensitive) following drought treatment and recovery. The data provided in Figure 1 represent the means of 5 measurements per accession. One-way ANOVA was used to assess the significance of the differences among treatments at each experimental stage, and Dunnett test at $P<0.05$ separated the means. Figures $1(\mathrm{a})$ and $1(\mathrm{~b})$ show the data of Fv/Fm and $\mathrm{PI}_{\mathrm{abs}}$ for both genotypes, respectively. Both genotypes showed a reduction in $\mathrm{Fv} / \mathrm{Fm}$ and the $\mathrm{PI}_{\mathrm{abs}}$ values at the end of drought treatment in comparison to their control values, with a smaller effect in \# 11434 than in \# 11431. After 24 hours of recovery, both $\mathrm{Fv} / \mathrm{Fm}$ and $\mathrm{PI}_{\text {abs }}$ values indicated recovery of \# 11434 to the relative values of control, while the chl fluorescence parameters in \# 11431 had not reached the level of the control values again. RWC was used as a parameter to directly assess the plant water status. RWC was reduced to about 40\% (\# 11431) and 50\% (\# 11434) following drought treatment, respectively. After 24 hours of rewatering, the initial water content was reached again in both genotypes (Figure 1(c)).

3.2. Proteomics. In the proteome analysis experiments, we used the Cy-2, Cy-3, and Cy-5 dyes for labeling protein extracts of control, drought, and $24 \mathrm{~h}$ recovered plants, respectively. This approach was used to allow the separation of samples from all three treatments of each genotype in one single gel under identical separation conditions to minimize false positive results due to differences in the running conditions between gels, which occasionally lead to misidentifications of presumably up- or downregulated proteins by automated scanning systems. The criterion for selecting proteins for MALDI-TOF-MS was a 1.5-fold threshold change in relative fluorescence signal intensity [20]. In \# 11434, out of the 650 detected spots on the 2D-PAGE, 12 protein spots were upregulated and 6 were downregulated in response to drought stress while 24 hours following recovery 13 protein spots were upregulated and 5 were downregulated. Out of 630 detected spots in \# 11431, 19 protein spots were upregulated and 4 were downregulated following drought stress and no protein spots were upregulated and 2 protein spots were downregulated after 24 hours of recovery. Figure 2 and Supplementary Figure 1 in Supplementary Material (available online at http://dx.doi.org/10.1155/2014/395905) represents the position of differentially expressed protein spots for both accessions in 2D gels that were picked for MALDI-TOF-MS analysis. Proteins were categorized into groups according to their function [23]. The proteins identified with MALDITOF-MS; their accession numbers on the NCBI database and their value of alteration in comparison to control values are indicated in Table 1.

3.3. Changes in the Group of "Metabolism" Proteins in Response to Drought and Recovery Treatments. The group of metabolism-related proteins [23] included the alteration of methionine synthase (spots 6,7), S-adenosylmethionine synthase (spot 16), and P-(S)-hydroxymandelonitrile lyase (spot 29). Methionine synthase (spot 6) was upregulated in both \# 11434 and \# 11431 following drought stress, while the more basic isoform (spot 7) was upregulated only in \# 11431. Following recovery, expression levels remained upregulated in \# 114134 and returned to control values in \# 11431. Methionine synthase has been found to increase under drought stress in roots of wild watermelon [24]. Several environmental stresses have been shown to cause changes in the pool of various free amino acids in plant cells from Arabidopsis and rice $[25,26]$. The activation of methionine synthase is an early response to drought since increased flux through the pathway provides a source of methyl groups for secondary metabolism under stress. Thus, the increase or maintenance of high levels of methionine synthase may reflect more active methionine and osmoregulant metabolism [27]. S-Adenosyl-L-methionine synthase has been found to be upregulated in response to drought in both \# 11434 and \# 11431, remaining increased in \# 11434, and reduced to the level of control 24 hours following recovery in \# 11431. It catalyzes the syntheses of S-adenosyl-L-methionine (SAM) from L-methionine and ATP. SAM is the major methylgroup donor for many transmethylation reactions in both prokaryotes and eukaryotes [28, 29]. Plants produce several secondary products that include one or more methyl groups added during their biosynthesis by methyltransferases, many of which use SAM as the methyl-group donor. SAM is also a precursor for the biosynthesis of polyamines which are involved in response to abiotic stresses [30]; in particular the polyamine spermine which is synthesized from putrescine via two steps using SAM was shown to have a protective role against drought stress [31]. SAM is further involved in lignin biosynthesis, a major step accelerated with lignification of water stressed Sorghum roots and salt stressed maize plants $[32,33]$. P-(S)hydroxymandelonitrile lyase was upregulated in \# 11431 following drought stress, but not following recovery. Hydroxynitrile lyases are involved in cyanogenesis, release of hydrogen cyanide from damaged tissues, and part of a defense mechanism against herbivores or fungi, respectively $[34,35]$. Their upregulation in response to drought stress might reflect 


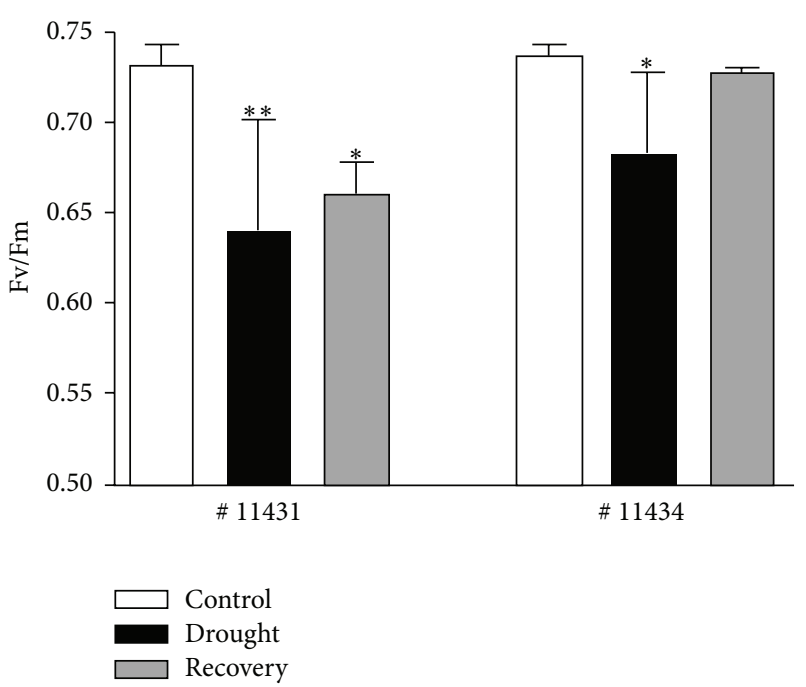

(a)

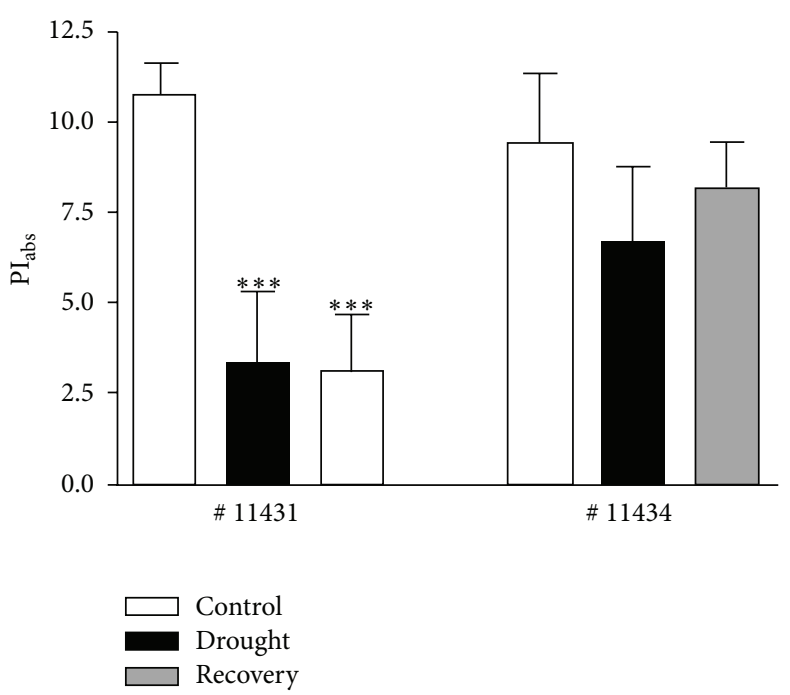

(b)

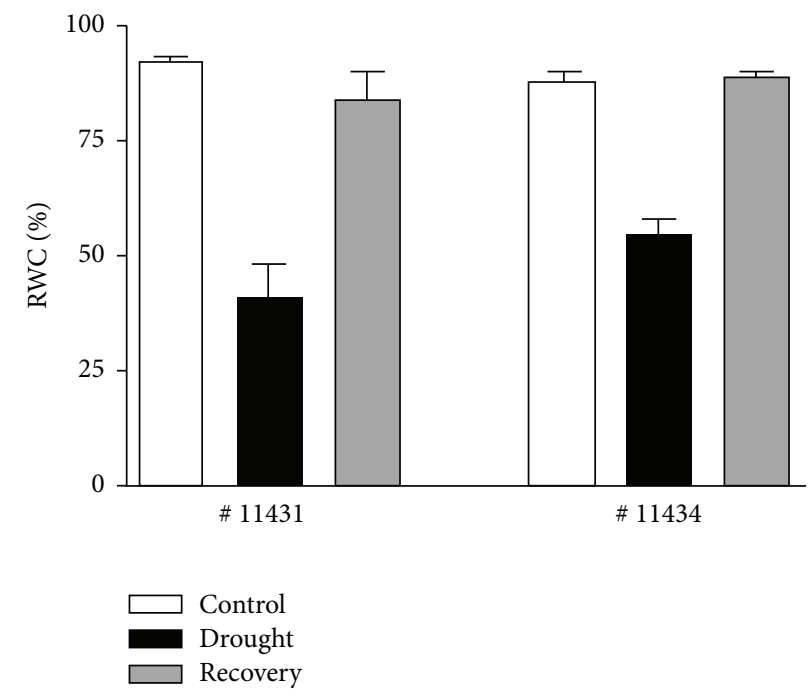

(c)

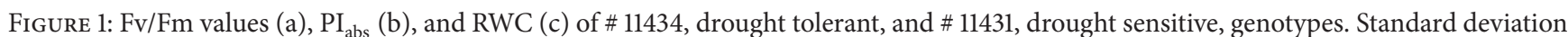
was calculated using 5 independent measurements. One-way ANOVA test was used to assess the significance of differences at $P<0.001$ $(* * *), P<0.01(* *)$, or $P<0.05(*)$ between treatments and their respective controls.

the damage of cells of the sensitive genotype or be explained as a cell death mechanism in response to drought stress.

\subsection{Changes in the Group of Proteins Involved in Energy} Metabolism. Two key enzymes of the C4-pathway showed significant changes in their abundance. For both lines drought stress induced an upregulation of PEPC content and a downregulation of NADP-ME. For Sorghum bicolor, three different PEPC isoforms are described which are expressed and regulated differentially [36]. The analysed isoform in this work was identified as the C4-Isoform (CP47). PEPC catalyses the primary carbon fixation in the mesophyll cells of C4 plants. Beyel and Brüggemann [37] investigated possible mechanisms of PEPC-regulation under drought stress for S. bicolor. First, C4 plants have to maintain a malate gradient to provide a carbon flow from the mesophyll to the cells of the bundle sheath [38]. It is therefore likely that the observed increased overall malate concentrations in S. bicolor under drought stress also imply a high malate concentration in the mesophyll cells. PEPC is activated via phosphorylation by a light-induced kinase (PEPC-kinase). Malate is an important inhibitor of the activity of PEPC as well as of PEPC-kinase. At a physiological pH of 7.3 malate concentrations of $5 \mathrm{mM}$ can cause an $80 \%$ reduction of the PEPC-activity. In addition, the inhibitory effect of malate could be enhanced by droughtinduced $\mathrm{pH}$ decrease [37]. The authors concluded that, despite high in vitro PEPC activities in drought stressed $S$. bicolor, the in vivo activities may be low enough to limit photosynthesis. From the regulation mechanisms of the PEPC-activity different conclusions can be drawn. On 


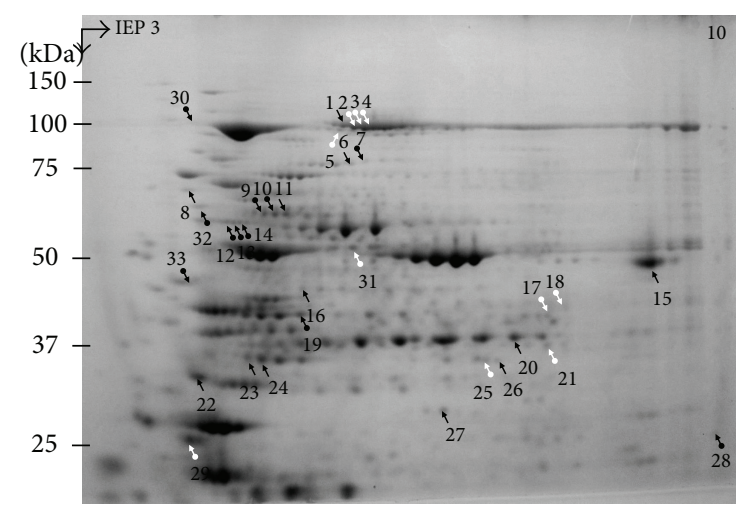

FIGURE 2: Differentially expressed proteins on 10\% SDS-PAGE following separation on $24 \mathrm{~cm}$ nonlinear strips pH 3-10, scanning, and staining with Colloidal Coomassie Brilliant Blue. Black arrows represent proteins expressed in both genotypes. Black arrows with round bottom represent expressed proteins in \# 11434, drought tolerant genotype, and white arrows with round bottom represent expressed proteins in \# 11431, drought sensitive, genotype.

the one hand plants may react with a compensation of decreased in vivo PEPC-activity by an increasing amount of the enzyme, explaining the increases of the PEPC isoforms of spots 1-4 in Figure 2. On the other hand, these isoforms may only showthe unphosphorylated, inactive population of the PEPC. Phosphorylation of a protein causes a decline of the PI. Figure 2 shows a much more prominent spot of PEPCequal mass $(100 \mathrm{kDa})$ in the acid part of the $2 \mathrm{D}-\mathrm{Gels}$, and it is likely that this spot represents the active population of the PEPC, while only the unphosphorylated or otherwise modified isoforms spots underwent concentration changes and were analysed. The changes of the abundance of the prominent spot were analysed subsequently and revealed a 1.7-fold decrease for \# 11431 under drought stress, while its abundance in the recovered plants of both lines and in the stressed plants of \# 11434 did not change strongly. Absence of the positive identification via mass-spec, however, has to be noticed. In future experiments, measurements of the in vitro PEPC-activity under identical experimental conditions in the two Egyptian landraces would help to interpret the results from the DIGE analysis. For NADP-ME both lines showed a decrease in abundance under drought stress (spots 9-11 for \# 11434 and spot 11 for \# 11431). As for the PEPC there are multiple spots identified as NADP-ME which differ in their PI. Beyel [39] and Alfonso and Brüggemann [40] showed a moderate reduction of the NADP-ME activity for Panicum bulbosum and Sorghum bicolor under drought stress. Downregulation of the NADP-ME activity leads to a decreased decarboxylation rate and a lowered malate consumption. This fact may explain the described accumulation of malate [37]. The lower decarboxylation rate in the bundle sheath cells may also influence total photosynthesis rate (Calvin-Cycle).

Pyruvate phosphate dikinase, PPDK (spot no. 30), was upregulated upon drought treatment only in \# 11434 both under drought and following recovery. However, the MALDITOF-MS data analysis did not indicate if it is the cytoplasmic or the chloroplastic form of the enzyme. The enzyme has been regarded as a putative rate limiting factor for C4 photosynthesis in Sorghum and other NADP-ME-C4 species under control conditions $[37,40,41]$. Under drought stress, in vitro activities exceeded the need for the observed photosynthesis rates. In naturally senescing leaves of C3 plants, both the cytosolic and chloroplastic isoforms of PPDK are upregulated: while cytosolic PPDK accumulates preferentially in veins, chloroplastic PPDK also accumulates in mesophyll cells [42]. In Arabidopsis, overexpression of PPDK during senescence can significantly accelerate nitrogen remobilization from leaves and thereby increase rosette growth rate and the weight and nitrogen content of seeds [42]. This function might be implemented as an efficient mobilization of metabolites from old to young leaves for plant survival under drought.

Changes in the levels of proteins that have an impact on photosynthesis, glycolysis, and TCA-cycle are also observed. Fructose-1,6-bisphosphate aldolase, FBA, is found in a cytosolic and a plastidic isoform in plants [43]. \#11431 revealed changes of both isoforms (upregulation of the cytosolic, downregulation of the plastidic isoform, spots 17, 23, and 24) under drought stress. \# 11434 showed a downregulation of the plastidic form only (spots 23, 24). Depending on the cellular localization, FBA has different functions. In the chloroplast the enzyme catalyzes the linkage of dihydroxyacetonephosphate and glycerine-3-phosphate to fructose1,6-bisphosphate and initiates the regeneration of ribulose1,5-bisphosphate, the $\mathrm{CO}_{2}$-acceptor of the Calvin cycle. The downregulation of plastidic FBA indicates a disturbance of the carbon fixation. Haake et al. [44] showed for transgenic tomatoes that a small decline of the FBA activity leads to lower rates of photosynthesis. Also the downregulation of glycerinaldehyd-3-phosphate dehydrogenase (GAPDH) influences photosynthesis. GAPDH is found in plastidic and cytosolic isoforms (spot no. 19, 20). In chloroplasts GAPDH catalyzes the reduction of 1,3-bisphosphoglycerate to produce glycerinaldehyd-3-phosphate. In conclusion, droughtinduced effects on the reductive as well as on the regenerative functions of the Calvin cycle have been observed. The downregulation of FBA and GAPDH under drought stress has recently also been observed by Gong et al. [45] for tomato.

In contrast to the plastidic isoforms, the cytosolic FBA in \# 11431 (spot 17) and GAPDH in \# 11431 and \# 11434 (spot no. 20) were found to be upregulated. In cytoplasm both enzymes play a role in glycolysis. Meanwhile, cytosolic aldehyde dehydrogenase which may also play a role in the detoxification of aldehydes which are produced under drought stress [46].

In addition, the stressed plants of \# 11431 indicated an increased amount of aconitase (spot no. 5). This enzyme catalyzes the reaction from citrate to isocitrate in the TCACycle. Besides its function in NADH production via the TCAcycle, isocitrate is essential for the glyoxylate-cycle and after oxidation to alpha-ketoglutarate it is used in the assimilation of nitrogen [47].

An upregulation of enzymes of glycolysis and respiration has most recently also been reported by Zhao et al. [48] for Cynodon sp. under drought stress, while photosynthetic carbohydrate production was suppressed. Plants may be forced 


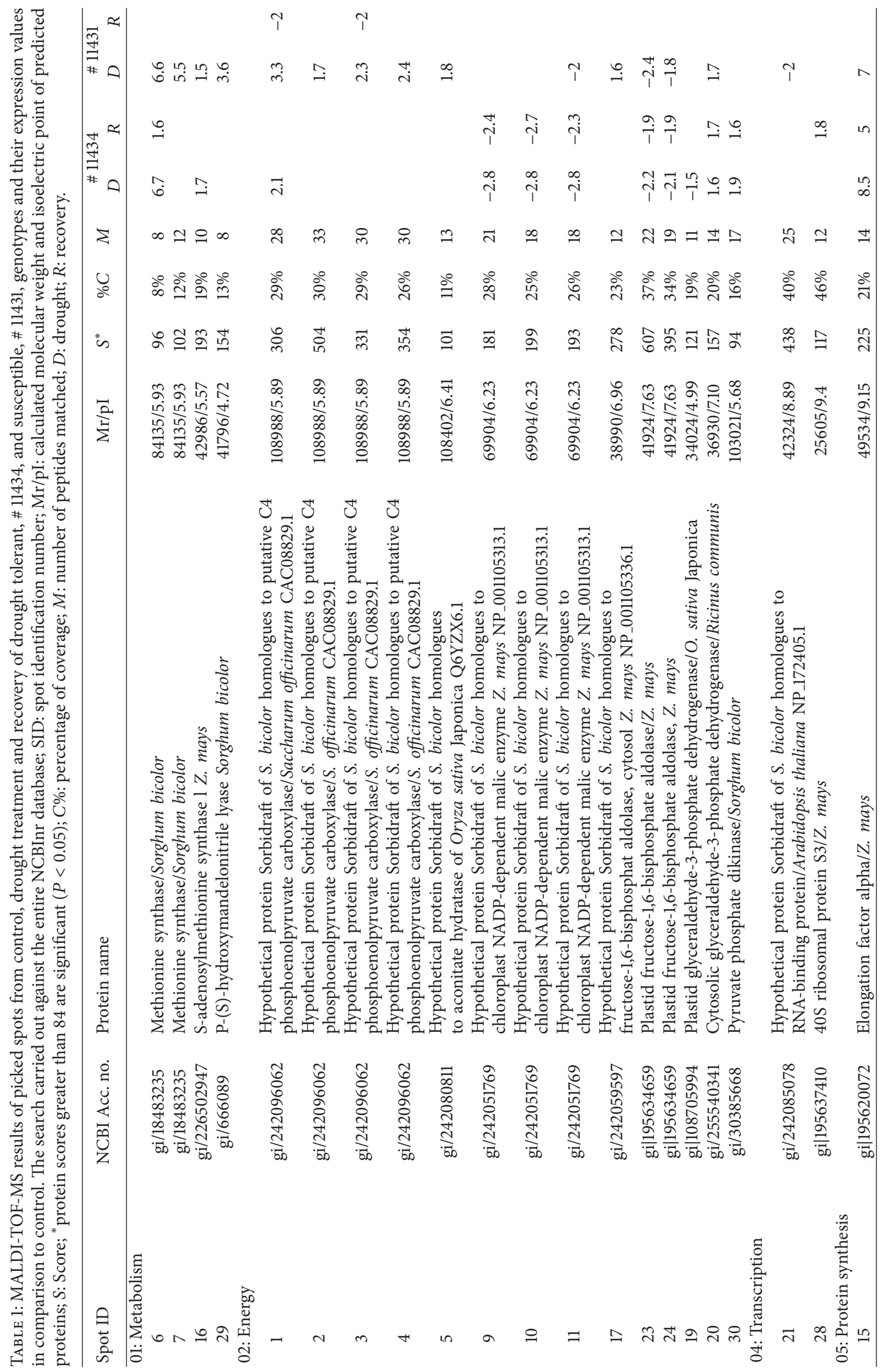




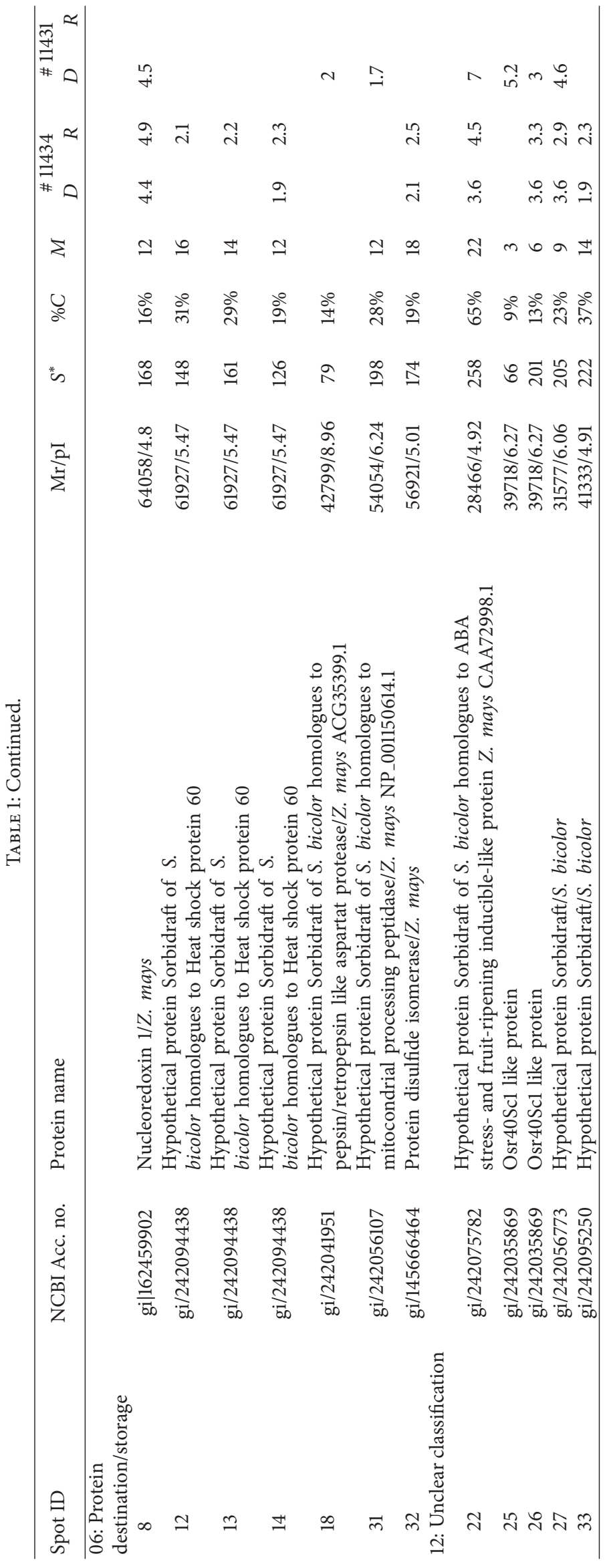


to increase catabolic reaction to maintain the metabolic and energetic homeostasis of the cells.

3.5. Changes in the Group of Proteins Relevant to Protein Destination and Storage. The chloroplastic form of heat shock protein 60 (Hsp60, spots 12-14) and disulfide isomerase (spot 32) were upregulated following drought stress after 24 hours of recovery in \#11434. Hsp60 is important in the assembly of plastid proteins such as Rubisco [49, 50]. It was suggested to be involved in folding and aggregation of many proteins that are transported to chloroplasts and mitochondria [51]. It binds different types of proteins after their transcription and before folding to prevent their aggregation [52]. In addition, another protein with chaperone functions, protein disulfide isomerase (PDI), was upregulated in drought stressed \# 11434. PDI catalyzes disulfide bond formation in the endoplasmic reticulum and assists in protein folding [50] and has been reported to be upregulated in bentgrass in response to drought stress and Thellungiella rosette in response to cold stress $[27,53]$. Pepsin/retropepsin dependent aspartate protease, APs, (spot 18) was only upregulated in \# 11431 following drought treatment. APs have been implicated in protein processing and/or degradation in different plant organs, as well as in plant senescence, stress responses, programmed cell death, and reproduction [54]. The expression of APs in the drought sensitive line might reflect the abundance of degraded proteins under drought stress. Similarly, mitochondrial processing peptidase, MPP, (spot 31) was upregulated only in \# 11431 following drought treatment. MPP is responsible for removing the presequence upon import via proteolytic cleavage and additionally it has a metalloprotease feature [55]. Nucleoredoxin, NRX, (spot 8) was upregulated following drought and recovery in \# 11434 while it was only upregulated following drought in \# 11431. NRX was isolated from maize [56]. This protein is located in the nucleus where it presumably catalyzes redox reactions. The presence of this protein in developing kernels indicates that it could regulate the activity of transcription factors, presumably by altering their redox state. This function might be extended to plants under drought stress.

3.6. Changes in the Groups of Transcription and Protein Synthesis-Involved Proteins. RNA binding protein (spot 21) was downregulated in \# 11431 following drought treatment and recovered to normal level following recovery, indicating RNA synthesis inhibition in the drought sensitive genotype. On the other hand, 40S ribosomal protein S3 (spot no. 28) was upregulated in \# 11343 following recovery. One of its important functions is to maintain the stability of $40 \mathrm{~S}$ ribosomal proteins. Elongation factor $\alpha$, EF $\alpha$, (spot no. 15) was upregulated in both genotypes after drought stress and remained upregulated during recovery only in \# 11434. EF1 $\alpha$ is responsible for efficient protein synthesis. These results might indicate more efficient RNA transcription and protein synthesis in the drought tolerant genotype especially following recovery.
3.7. Proteins with Unclear Classification. Several proteins were upregulated in response to drought stress and following recovery (Table 1). Of these is the ABA stress- and fruitripening induced like protein (spot 22). It was found to be upregulated in both the drought sensitive and tolerant genotypes. However it remained upregulated following the recovery of the tolerant genotype. It was suggested that ABA stress- and fruit-ripening induced like protein might adjust the activity of other gene products via its DNA-binding activity or it might function as a protective agent against DNA damage at the earlier stages of stress [57].

\section{Conclusion}

The drought tolerant genotype proteome analysis indicated that the combined activities of several protein groups may enable the plants to tolerate drought stress and efficiently recover after removing the stress conditions. An efficient mechanism for protein stability, reallocation of metabolites to the newly developed structures, and efficient protein synthesis are the most characteristic features obtained from this study. On the other hand, elements of cell death combined with the production of proteases were the most obvious characteristic for the drought sensitive genotype.

\section{Conflict of Interests}

The authors declare that there is no conflict of interests regarding the publication of this paper.

\section{Authors' Contribution}

Christoph Jedmowski and Ahmed Ashoub contributed equally to this work.

\section{Acknowledgments}

The authors would like to thank the Egyptian National Gene Bank, Agricultural Research Center, for providing the seed material of the accession numbers used in this study. This study was funded by the research funding programme "LOEWE-Landes-Offensive zur Entwicklung Wissenschaftlich-ökonomischer Exzellenz" of Hesse's Ministry of Higher Education, Research, and the Arts.

\section{References}

[1] S. A. Anjum, X.-Y. Xie, L.-C. Wang, M. F. Saleem, C. Man, and W. Lei, "Morphological, physiological and biochemical responses of plants to drought stress," African Journal of Agricultural Research, vol. 6, no. 9, pp. 2026-2032, 2011.

[2] J. S. Boyer, "Plant productivity and environment," Science, vol. 218, no. 4571, pp. 443-448, 1982.

[3] H.-B. Shao, L.-Y. Chu, C. A. Jaleel, P. Manivannan, R. Panneerselvam, and M.-A. Shao, "Understanding water deficit stressinduced changes in the basic metabolism of higher plantsbiotechnologically and sustainably improving agriculture and the ecoenvironment in arid regions of the globe," Critical Reviews in Biotechnology, vol. 29, no. 2, pp. 131-151, 2009. 
[4] N. Tuteja, "Abscisic acid and abiotic stress signaling," Plant Signaling \& Behavior, vol. 2, no. 3, pp. 135-138, 2007.

[5] K. Shinozaki and K. Yamaguchi-Shinozaki, "Gene networks involved in drought stress response and tolerance," Journal of Experimental Botany, vol. 58, no. 2, pp. 221-227, 2007.

[6] K. Shinozaki, K. Yamaguchi-Shinozaki, and M. Seki, "Regulatory network of gene expression in the drought and cold stress responses," Current Opinion in Plant Biology, vol. 6, no. 5, pp. 410-417, 2003.

[7] J. Bailey-Serres, "Selective translation of cytoplasmic mRNAs in plants," Trends in Plant Science, vol. 4, no. 4, pp. 142-148, 1999.

[8] S. Mahajan and N. Tuteja, "Cold, salinity and drought stresses: an overview," Archives of Biochemistry and Biophysics, vol. 444, no. 2, pp. 139-158, 2005.

[9] P. Baskaran and N. Jayabalan, "In vitro plant regeneration and mass propagation system for Sorghum bicolor-a valuable major cereal crop," Journal of Agricultral Technology, vol. 1, pp. 345-363, 2005.

[10] A. H. Paterson, J. E. Bowers, R. Bruggmann et al., "The Sorghum bicolor genome and the diversification of grasses," Nature, vol. 457, no. 7229, pp. 551-556, 2009.

[11] C. Jedmowski, A. Ashoub, and W. Brüggemann, "Reactions of Egyptian landraces of Hordeum vulgare and Sorghum bicolor to drought stress, evaluated by the OJIP fluorescence transient analysis," Acta Physiologiae Plantarum, vol. 35, no. 2, pp. 345354, 2013.

[12] B. J. Strasser and R. J. Strasser, "Measuring fast fluorescence transients to address environmental questions: the JIP test," in Photosynthesis: From Light to Biosphere, P. Mathis, Ed., pp. 977980, Kluwer Academic, Amsterdam, The Netherlands, 1995.

[13] R. E. Smart and G. E. Bingham, "Rapid estimates of relative water content," Plant Physiology, vol. 53, pp. 258-260, 1974.

[14] R. J. Strasser and A. Srivastava, "Polyphasic chlorophyll a fluorescence transient in plants and cyanobacteria," Photochemistry and Photobiology, vol. 61, no. 1, pp. 32-42, 1995.

[15] V. Méchin, C. Damerval, and M. Zivy, “Total protein extraction with TCA-acetone," Methods in Molecular Biology, vol. 355, pp. $1-8,2007$.

[16] M. M. Bradford, "A rapid and sensitive method for the quantitation of microgram quantities of protein utilizing the principle of protein dye binding," Analytical Biochemistry, vol. 72, no. 1-2, pp. 248-254, 1976.

[17] U. K. Laemmli, "Cleavage of structural proteins during the assembly of the head of bacteriophage T4," Nature, vol. 227, no. 5259, pp. 680-685, 1970.

[18] A. Ashoub, T. Beckhaus, T. Berberich, M. Karas, and W. Brüggemann, "Comparative analysis of barley leaf proteome as affected by drought stress," Planta, vol. 237, no. 3, pp. 771-781, 2013.

[19] C. Rode, K. Lindhorst, H.-P. Braun, and T. Winkelmann, "From callus to embryo: a proteomic view on the development and maturation of somatic embryos in Cyclamen persicum," Planta, vol. 235, no. 5, pp. 995-1011, 2012.

[20] A. K. Swami, S. I. Alam, N. Sengupta, and R. Sarin, “Differential proteomic analysis of salt stress response in Sorghum bicolor leaves," Environmental and Experimental Botany, vol. 71, no. 2, pp. 321-328, 2011.

[21] G. H. Krause and E. Weis, "Chlorophyll fluorescence and photosynthesis: the basics," Annual Review of Plant Physiology and Plant Molecular Biology, vol. 42, no. 1, pp. 313-349, 1991.
[22] A. Oukarroum, S. E. Madidi, G. Schansker, and R. J. Strasser, "Probing the responses of barley cultivars (Hordeum vulgare L.) by chlorophyll a fluorescence OLKJIP under drought stress and re-watering," Environmental and Experimental Botany, vol. 60, no. 3, pp. 438-446, 2007.

[23] H. W. Mewes, K. Albermann, M. Bähr et al., "Overview of the yeast genome," Nature, vol. 387, no. 6632, pp. 7-65, 1997.

[24] K. Yoshimura, A. Masuda, M. Kuwano, A. Yokota, and K. Akashi, "Programmed proteome response for drought avoidance/tolerance in the root of a C3 xerophyte (wild watermelon) under water deficits," Plant and Cell Physiology, vol. 49, no. 2, pp. 226-241, 2008.

[25] B. K. Ndimba, S. Chivasa, W. J. Simon, and A. R. Slabas, "Identification of Arabidopsis salt and osmotic stress responsive proteins using two-dimensional difference gel electrophoresis and mass spectrometry," Proteomics, vol. 5, no. 16, pp. 41854196, 2005.

[26] S. Yan, Z. Tang, W. Su, and W. Sun, "Proteomic analysis of salt stress-responsive proteins in rice root," Proteomics, vol. 5, no. 1, pp. 235-244, 2005.

[27] E. B. Merewitz, T. Gianfagna, and B. Huang, "Protein accumulation in leaves and roots associated with improved drought tolerance in creeping bentgrass expressing an ipt gene for cytokinin synthesis," Journal of Experimental Botany, vol. 62, no. 15, pp. 5311-5333, 2011.

[28] C. W. Tabor and H. Tabor, "Methionine adenosyltransferase (S-adenosylmethionine synthetase) and S-adenosylmethionine decarboxylase," Advances in Enzymology and Related Areas of Molecular Biology, vol. 56, pp. 251-282, 1984.

[29] W. Boerjan, G. Bauw, M. van Montagu, and D. Inze, "Distinct phenotypes generated by overexpression and suppression of Sadenosyl-L-methionine synthetase reveal developmental patterns of gene silencing in tobacco," Plant Cell, vol. 6, no. 10, pp. 1401-1414, 1994.

[30] S. S. Gill and N. Tuteja, "Reactive oxygen species and antioxidant machinery in abiotic stress tolerance in crop plants," Plant Physiology and Biochemistry, vol. 48, no. 12, pp. 909-930, 2010.

[31] K. Yamaguchi, Y. Takahashi, T. Berberich et al., "A protective role for the polyamine spermine against drought stress in Arabidopsis," Biochemical and Biophysical Research Communications, vol. 352, no. 2, pp. 486-490, 2007.

[32] H. Azaizeh and E. Steudle, "Effects of salinity on water transport of excised maize (Zea mays L.) roots," Plant Physiology, vol. 97, no. 3, pp. 1136-1145, 1991.

[33] R. T. Cruz, W. R. Jordan, and M. C. Drew, "Structural changes and associated reduction of hydraulic conductance in roots of Sorghum bicolor L. following exposure to water deficit," Plant Physiology, vol. 99, no. 1, pp. 203-212, 1992.

[34] A. Nahrstedt, "Cyanogenic compounds as protecting agents for organisms," Plant Systematics and Evolution, vol. 150, no. 1-2, pp. 35-47, 1985.

[35] D. S. Seigler, "Cyanide and cyanogenic glycosides," in Herbivores, Their Interactions with Secondary Plant Metabolites, G. A. Rosenthal and M. R. Berebaum, Eds., pp. 35-77, Academic Press, New York, NY, USA, 1991.

[36] L. Lepiniec, E. Keryer, H. Philippe, P. Gadal, and C. Crétin, "Sorghum phosphoenolpyruvate carboxylase gene family: structure, function and molecular evolution," Plant Molecular Biology, vol. 21, no. 3, pp. 487-502, 1993.

[37] V. Beyel and W. Brüggemann, "Differential inhibition of photosynthesis during pre-flowering drought stress in Sorghum 
bicolor genotypes with different senescence traits," Physiologia Plantarum, vol. 124, no. 2, pp. 249-259, 2005.

[38] R. C. Leegood, “The intercellular compartmentation of metabolites in leaves of Zea mays L.," Planta, vol. 164, no. 2, pp. 163-171, 1985.

[39] V. Beyel, Wirkung von Trockenstress auf verschiedene Kultivare von Sorghum bicolor [Ph.D. thesis], Johann Wolfgang GoetheUniversität, Frankfurt am Main, Germany, 2003.

[40] S. U. Alfonso and W. Brüggemann, "Photosynthetic responses of a C3 and three C 4 species of the genus Panicum (s.l.) with different metabolic subtypes to drought stress," Photosynthesis Research, vol. 112, no. 3, pp. 175-191, 2012.

[41] M. C. Dias and W. Brüggemann, "Differential inhibition of photosynthesis under drought stress in Flaveria species with different degrees of development of the C4 syndrome," Photosynthetica, vol. 45, no. 1, pp. 75-84, 2007.

[42] L. Taylor, A. Nunes-Nesi, K. Parsley et al., "Abscisic acid and abiotic stress signaling," Plant Signaling and Behavior, vol. 2, no. 3, pp. 135-138, 2007.

[43] H. G. Lebherz, M. M. Leadbetter, and R. A. Bradshaw, "Isolation and characterization of the cytosolic and chloroplast forms of spinach leaf fructose diphosphate aldolase," Journal of Biological Chemistry, vol. 259, no. 2, pp. 1011-1017, 1984.

[44] V. Haake, R. Zrenner, U. Sonnewald, and M. Stitt, "A moderate decrease of plastid aldolase activity inhibits photosynthesis, alters the levels of sugars and starch, and inhibits growth of potato plants," Plant Journal, vol. 14, no. 2, pp. 147-157, 1998.

[45] P. Gong, J. Zhang, H. Li et al., "A moderate decrease of plastid aldolase activity inhibits photosynthesis, alters the levels of sugars and starch, and inhibits growth of potato plants," Plant Journal, vol. 14, no. 2, pp. 147-157, 1998.

[46] S. O. Kotchoni and D. Bartels, "Water stress induces the upregulation of a specific set of genes in plants: aldehyde dehydrogenase as an example," Bulgarian Journal of Plant Physiology, pp. 37-51, 2003.

[47] T. N. Popova and M. Â. A. Pinheiro de Carvalho, "Citrate and isocitrate in plant metabolism," Biochimica et Biophysica ActaBioenergetics, vol. 1364, no. 3, pp. 307-325, 1998.

[48] Y. Zhao, H. Du, Z. Wang, and B. Huang, "Identification of proteins associated with water-deficit tolerance in C4 perennial grass species, Cynodon dactylon $\times$ Cynodon transvaalensis and Cynodon dactylon," Physiologia Plantarum, vol. 141, no. 1, pp. 40-55, 2011.

[49] E. Vierling, "The roles of heat shock proteins in plants," Annual Review of Plant Physiology and Plant Molecular Biology, vol. 42, no. 1, pp. 579-620, 1991.

[50] W. Wang, B. Vinocur, O. Shoseyov, and A. Altman, "Role of plant heat-shock proteins and molecular chaperones in the abiotic stress response," Trends in Plant Science, vol. 9, no. 5, pp. 244-252, 2004.

[51] T. H. Lubben, G. K. Donaldson, P. V. Viitanen, and A. A. Gatenby, "Several proteins imported into chloroplasts form stable complexes with the GroEL-related chloroplast molecular chaperone," Plant cell, vol. 1, no. 12, pp. 1223-1230, 1989.

[52] D. A. Parsell and S. Lindquist, "The function of heat-shock proteins in stress tolerance: degradation and reactivation of damaged proteins," Annual Review of Genetics, vol. 27, pp. 437496, 1993.

[53] F. Gao, Y. Zhou, W. Zhu, X. Li, L. Fan, and G. Zhang, "Proteomic analysis of cold stress-responsive proteins in Thellungiella rosette leaves," Planta, vol. 230, no. 5, pp. 1033-1046, 2009.
[54] I. Simões and C. Faro, "Structure and function of plant aspartic proteinases," European Journal of Biochemistry, vol. 271, no. 11, pp. 2067-2075, 2004.

[55] S. Mackenzie and L. McIntosh, "Higher plant mitochondria," Plant Cell, vol. 11, no. 4, pp. 571-585, 1999.

[56] B. J. Laughner, P. C. Sehnke, and R. J. Ferl, "A novel nuclear member of the thioredoxin superfamily," Plant Physiology, vol. 118, no. 3, pp. 987-996, 1998.

[57] Y. Kalifa, E. Perlson, A. Gilad, Z. Konrad, P. A. Scolnik, and D. Bar-Zvi, "Over-expression of the water and salt stress-regulated Asrl gene confers an increased salt tolerance," Plant, Cell and Environment, vol. 27, no. 12, pp. 1459-1468, 2004. 



Submit your manuscripts at

http://www.hindawi.com

Journal of
Signal Transduction
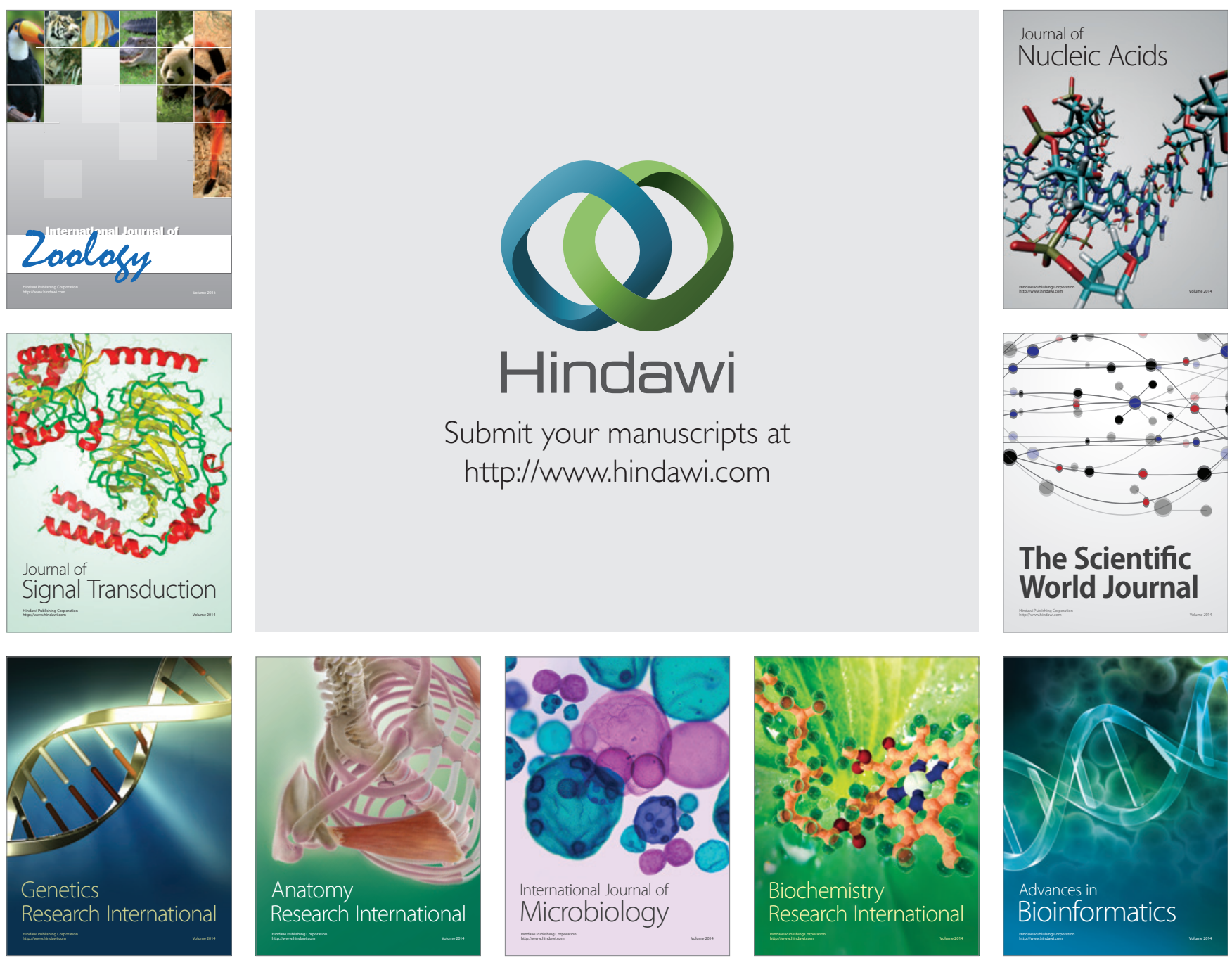

The Scientific World Journal
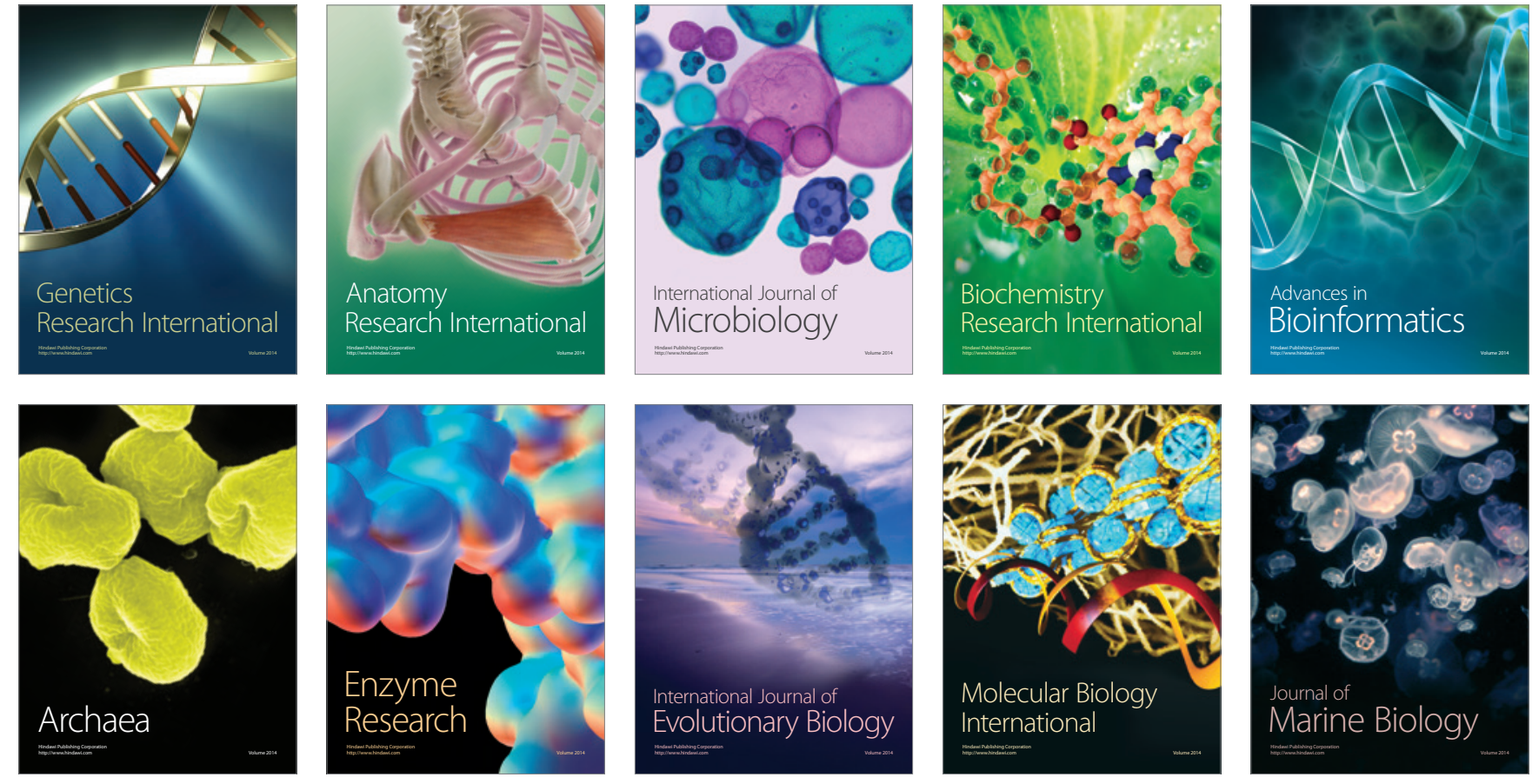